\title{
The emerging roles of GPRC5A in diseases
}

\author{
Honglei Zhou ${ }^{1}$ and Isidore Rigoutsos ${ }^{1}$ \\ ${ }^{1}$ Computational Medicine Center, Jefferson Alumni Hall, Thomas Jefferson University, Philadelphia, PA \\ Correspondence to: Isidore Rigoutsos, email: isidore.rigoutsos@jefferson.edu \\ Keywords: GPRC5A, RA13, tumor suppressor, oncogene, dual-behavior, cancer \\ Received: November 18, $2014 \quad$ Accepted: November 24, $2014 \quad$ Published: November 25, 2014
}

This is an open-access article distributed under the terms of the Creative Commons Attribution License, which permits unrestricted use, distribution, and reproduction in any medium, provided the original author and source are credited.

\section{ABSTRACT}

The 'Retinoic Acid-Inducible G-protein-coupled receptors' or RAIG are a group comprising the four orphan receptors GPRC5A, GPRC5B, GPRC5C and GPRC5D. As the name implies, their expression is induced by retinoic acid but beyond that very little is known about their function. In recent years, one member, GPRC5A, has been receiving increasing attention as it was shown to play important roles in human cancers. As a matter of fact, dysregulation of GPRC5A has been associated with several cancers including lung cancer, breast cancer, colorectal cancer, and pancreatic cancer. Here we review the current state of knowledge about the heterogeneity and evolution of GPRC5A, its regulation, its molecular functions, and its involvement in human disease.

\section{INTRODUCTION}

The $\mathrm{G}$ protein-coupled receptor, class $\mathrm{C}$, group 5, member A (GPRC5A), also known as Retinoic acidinduced gene 3 (RAI3) or Retinoic acid-induced gene 1 (RAIG1) was first cloned in 1998 [1]. GPRC5A is primarily expressed in lung and lowly expressed or absent in other tissues (Figure 1A). In normal tissues the GPRC5A protein mainly locates at plasma membrane, perinuclear vesicle, endoplasmic reticulum, Golgi apparatus and extracellular vesicular exosomes [1-5] - see also the Human Protein Atlas at www.proteinatlas.org. Previous GPRC5A studies indicated that it plays important roles and that its dysregulation could result in many different types of cancer in humans (Figure 1B) as well as other diseases [513]. To better understand the field of GPRC5A research, here we summarize and discuss what is currently known about this gene and its protein.

\section{Heterogeneity and Evolution of GPRC5A gene}

GPRC5A is expressed in different mammals and other tetrapods as well as in birds, reptiles, amphibians, and fish [14]. Phylogenetic analysis shows that the amino acid sequence of human GPRC5A shares a high percentage of sequence identity with orthologues from other species, indicating that it has been conserved in evolution: 99\% with Pan troglodytes, $76 \%$ with Mus musculus, 55\% with
Columba livia, 52\% with Ophiophagus Hannah, and 46\% with Xenopus laevis. See also Figure 2A. In addition to GPRC5A, there are three more members in this group of receptors, each with different degrees of evolutionary conservation. Amino acid sequence alignment of the four members shows that GPRC5A shares 31\% 42\% sequence identity with the other three members $[15,16]$ - see also Figure 2B. The four members of group 5 receptors have high sequence identity within the transmembrane segments while the major difference occurs at $\mathrm{N}$-terminus. The N-termini of GPRC5A and GPRC5D are shorter than those of GPRC5B and GPRC5C. On the other hand, both GPRC5B and GPRC5C contain highly conserved cysteines in the first and second extracellular loops (highlighted in Figure 2B), but GPRC5A and GPRC5D lack this residue [15]. In the absence of a long N-terminus, it's unlikely that GPRC5A can bind an agonist at its amino-terminus domain. Instead, agonists may bind to the 7 transmembrane (TM) of GPRC5A, GPRC5B, GPRC5C and GPRC5D, similarly to class A GPCRs $[15,17,18]$. Currently, no ligand is known for any of the members of RAIG. The human GPRC5A gene contains many Single Nucleotide Polymorphisms (SNPs) in its 5' untranslated regions (5'UTR), its coding region, and its $3^{\prime}$ UTR (listed in Additional file 1): whether these variants have any functional impact (through post-transcriptional effects or changes in the amino acid sequence) is not currently known. 


\section{Transcriptional Regulation of GPRC5A}

GPRC5A was first identified as a retinoic acidinduced gene and its locus contains a novel retinoic acid response element (RARE) at its proximal 5' upstream region (Figure 3) [19]. In the absence of retinoic acid, retinoic acid receptors bind to the RARE as RAR/RXR heterodimers $[20,21]$, recruiting co-repressor proteins and repressing GPRC5A gene transcription. Binding of agonist ligands to RAR/RXRs results in dissociation of corepressor and recruitment of co-activator proteins, which in turn promotes GPRC5A gene transcription (Figure 4) $[19,22-26]$.

The GPRC5A gene locus also contains p53 consensus DNA binding sequences in the promoter region (Figure 3 and Figure 4) [27]. Overexpression of wild-type p53 represses GPRC5A expression in 2774qw1 human ovarian tumor cell line [27]. Both microarray and quantitative RT-PCR in MDA-MB-468, BT-20, BT-549, and SK-BR-3 cells which contain mutant p53 and in T47D, MCF7, ZR-75-1, and BT474 cells which contain wild type $\mathrm{p} 53$ show that GPRC5A mRNA is up-regulated in p53 mutated cell lines [27]. Besides p53 and retinoid acid, GPRC5A could be regulated by cAMP as there is a cAMP-responsive element (CRE) in its promoter region and GPRC5A's expression could be induced by cAMP signaling (Figure 3 and Figure 4). Interestingly, cAMP and retinoic acid might synergistically regulate GPRC5A expression [28]. In addition to these three regulatory elements in promoter region, the ENCODE project has identified several additional transcription factors that bind to GPRC5A promoter region (Figure 3 and Additional file 2 and http://genome.ucsc.edu/).

The GPRC5A gene locus contains multiple BRCA1 binding sites (Figure 3). BRCA1 could work either as an activator or as a repressor by association with different other transcription factors [13, 29-37]. A previous study showed that knockdown of BRCA1 results in down-
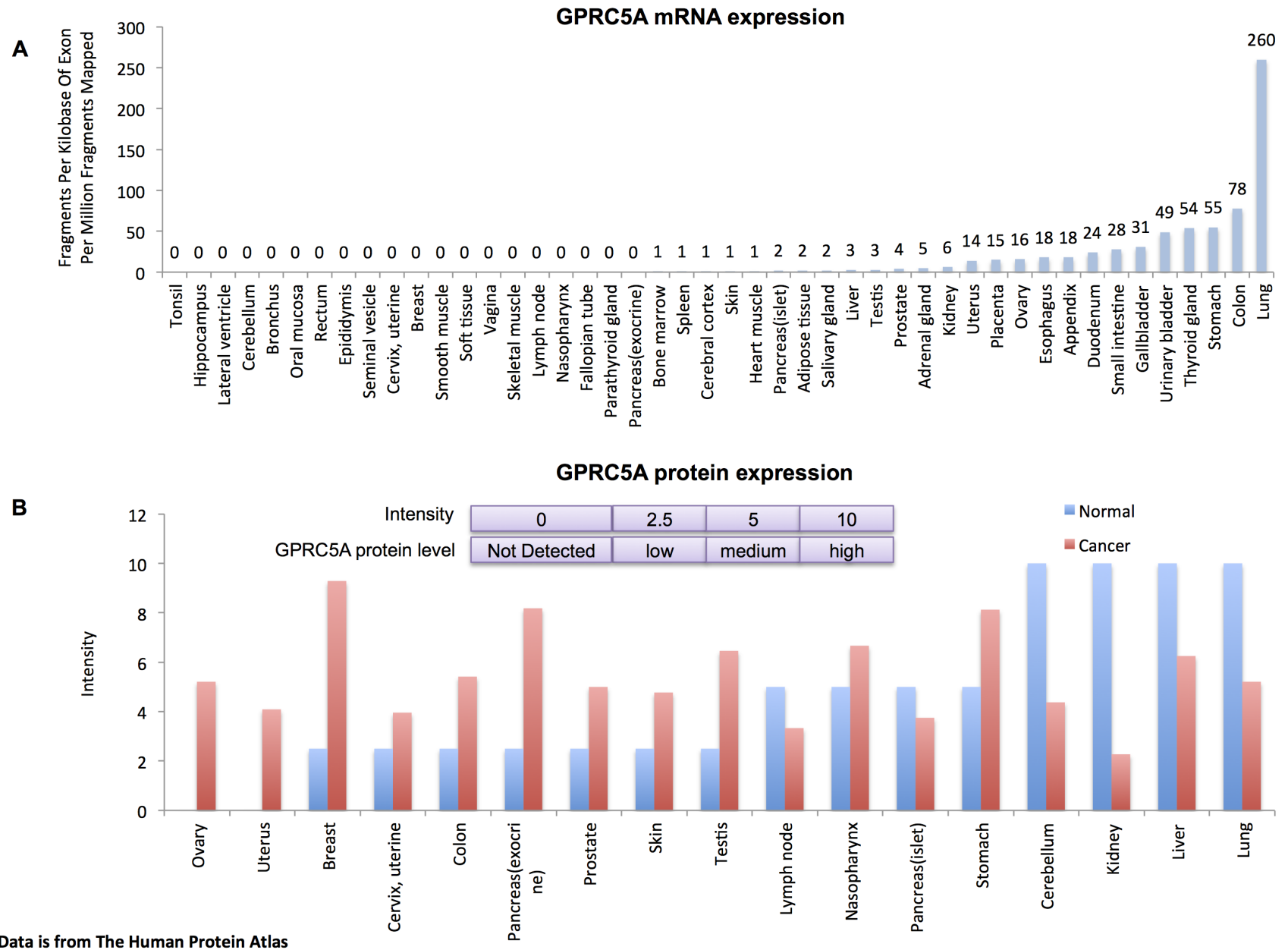

Figure 1: GPRC5A expression. A. Levels of expression of $m R N A$ in different organs and tissues. mRNA expression is measured by using RNA-seq. The expression levels are plotted as number of Fragments Per Kilobase of Exon Per Million Fragments Mapped. B. Expression of protein in different organs and tissues in both normal and cancer. Protein levels are measured by using immunohistochemistry. Different intensities indicate different expression levels. The Figure was compiled using data is from The Human Protein Atlas http://www. proteinatlas.org/. 
regulation of GPRC5A expression [13], suggesting that BRCA1 may work as a positive activator of GPRC5A expression. The locus also contains FOS and JUN binding sites (Figure 3). FOS and JUN are encoded by protooncogenes and bind to each other to form the Activator Protein-1 (AP-1) complex, which could in turn activate gene transcription [38-40]. AP-1 activity is usually induced by stimulations such as growth factors, proinflammatory cytokines and is UV-radiation-dependent on the MAPK cascade, JNK and p38 [38, 41-43]. As GPRC5A expression could be induced by serum in cell culture [27, 44], it is very likely that FOS and JUN binding sites within GPRC5A gene are functional.

Another transcription factor MYC also binds to GPRC5A promoter region in some cancer cells like HeLa and $\mathrm{HepG} 2$ cells (Figure 3), whereas not in embryonic stem (ES) cells [45]. GPRC5A expression level is lower in ES cells than trophoblast and overexpression of MYC in ES cells down-regulate GPRC5A mRNA [45].

\section{Post-transcriptional Regulation of GPRC5A}

MicroRNAs (miRNAs) are small non-coding RNAs that function as transcriptional and post-transcriptional

regulators of gene expression [46] and would be among the first candidates to post-transcriptionally regulate GPRC5A. However, very little is currently known in this regard. In a recent report, GPRC5A mRNA was shown to be targeted at its $5^{\prime}$ UTR by miR-103a-3p in pancreatic cells [47]. This is a very interesting finding considering that currently only a handful of examples are known in the literature where targeting of a $5^{\prime}$ UTR by a miRNA leads to the down-regulation of the respective mRNA (Figure 4). In this particular case, it was shown that overexpression of miR-103a-3p reduces both GPRC5A mRNA and protein in cells. In addition to miR-103a-3p, computational predictions (Table 1) using the rna22 algorithm [48, 49] suggest that many other putative miRNA target sites are present along the length of GPRC5A's mRNA.

Among the important post-transcriptional regulators are also RNA binding proteins (RBPs) [50] as well as long non-coding RNAs (lncRNAs) [51-54]. Both are suspected of playing roles in post-transcriptionally regulating GPRC5A but no data are available at this time [55-57].
A

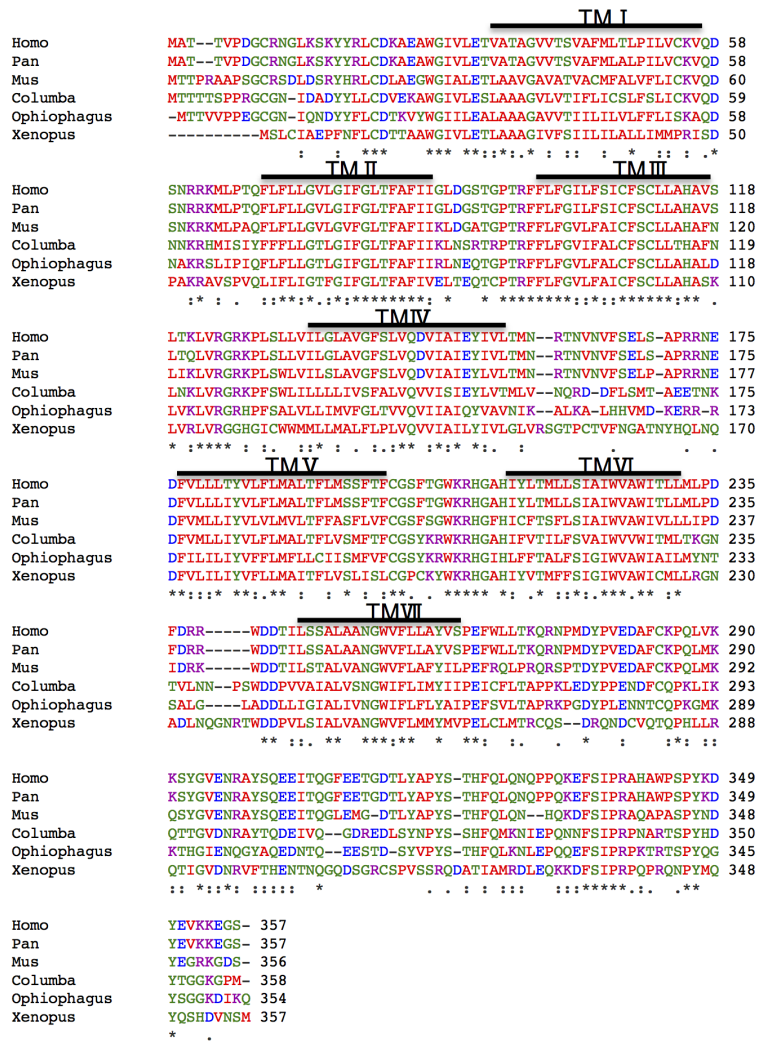

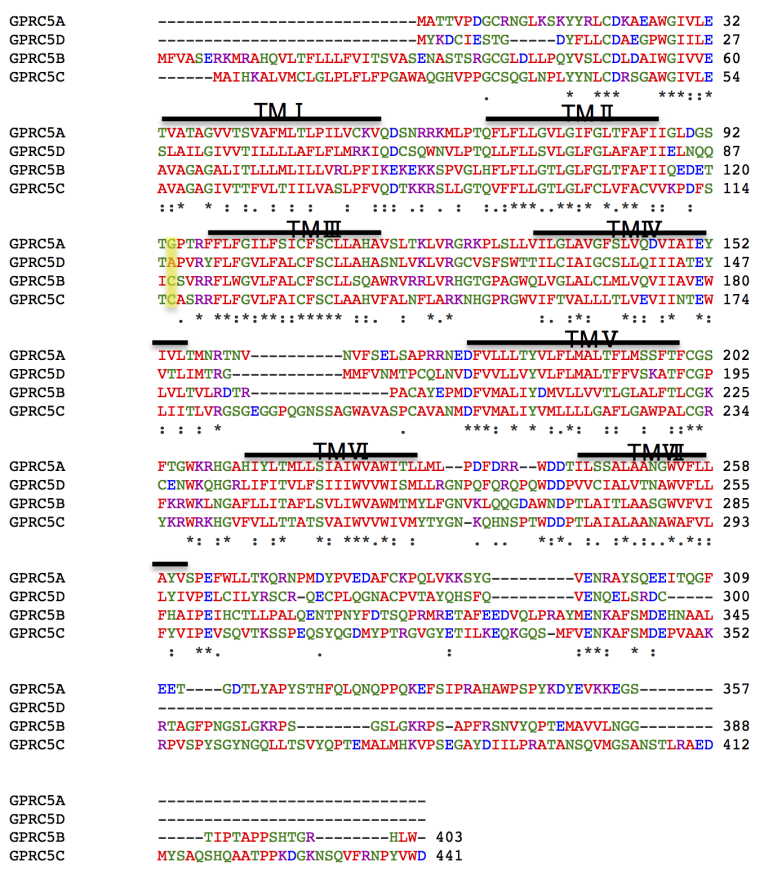

Figure 2: A. Alignment of human GPRC5A across several species. Identical $\left(^{*}\right)$ and conservatively substituted (:) amino acids are indicated. Gaps are shown with "-" whereas putative TM segments are over-lined. B. Alignment of the four receptors from the human class C group 5. Identical (*) and conservatively substituted (:) amino acids are indicated. Gaps are shown with "“-” whereas putative TM segments are over-lined. 
Table 1: Number of distinct miRBase miRNAs and target sites that rna22 predicts target GPRC5A (P-val $\leq$ 0.05).

\begin{tabular}{|c|c|c|}
\hline Region & $\begin{array}{c}\text { Number of targeting miRNAs } \\
\text { (predicted) }\end{array}$ & $\begin{array}{c}\text { Number of } \\
\text { Targeting sites } \\
\text { (predicted) }\end{array}$ \\
\hline 5'UTR & 343 & 98 \\
\hline CDS & 595 & 223 \\
\hline 3'UTR & 1170 & 922 \\
\hline
\end{tabular}

\section{Molecular function of GPRC5A}

As stated above, GPRC5A's short $\mathrm{N}$ terminus makes it unlikely that it binds ligands through that region [15]. Chimeric receptors with the N-terminus of the metabotropic glutamate receptor 1 (mGluR1) and the 7 TM region of GPRC5A could bind mGluR1 ligands [40], but is not activated [15]. This indicates that the signaling transduction cascade may differ in the case of GPRC5A from other class C GPCRs. Interestingly, overexpression of GPRC5A in Nthy-ori 3-1 cells downregulated Gs $\alpha$ expression and reduced intracellular cAMP levels compared to cells transfected with the empty vector [28]. In turn, cAMP signaling could mediate GPRC5A expression by cAMP-responsive element (CRE) motif close to GPRC5A gene's transcription initiation site [28]. The results indicate GPRC5A may form a feedback loop in regulating cAMP signaling.

In addition to cAMP signaling, GPRC5A is also involved in the NF- $\mathrm{KB}$ and STAT3 signaling pathways $[58,59]-$ see also Figure 4 . Knockout of GPRC5A in

A
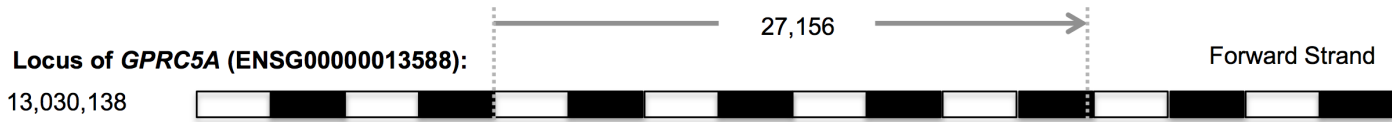

$13,084,449$ $13,030,138$

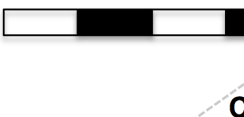

C NIV

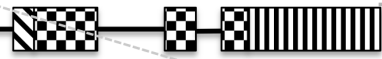

GPRC5A mRNA: ENST00000014914

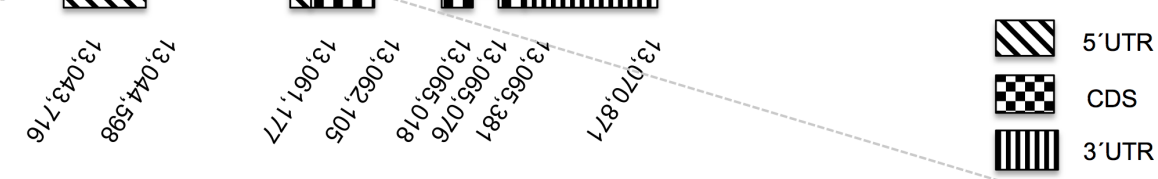

B AATTTCATCT GGCGCCCCCG TTCAATCA

$13,043,716$

$13,043,796$ BRCA1 BRCA1

GC CTGCATTGTC

GAGGCTTTA

GAGAGGCAGT TAGGAAAGGA GAGATACTGA

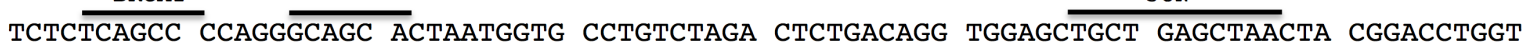
$\mathrm{MYC} / \mathrm{MAX}$

$13,043,876$

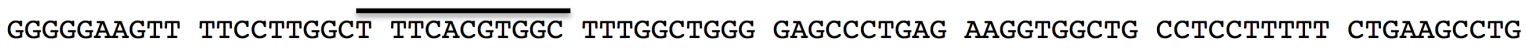

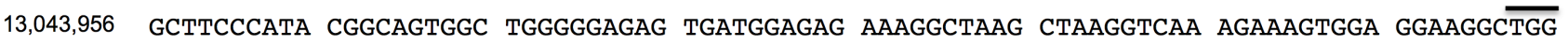
13,044,036 CTTGTCCCGC TGGACTTGAC GGCGAGCTG CTGCAATCTC GCGgGCTGGg CCCTTGCCCC GGGTGGACCC GAGTGCCTGC

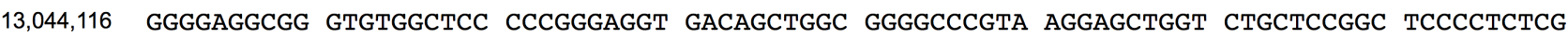
P53

13,044,196 TAGCCGGCGC CCTGGGACCA GCGCGTGAGC ACGTCTCGGA GGAGTCCGAT GCGCTGGGCA GGGCCGGGTG GTCACCCCCG 13,044,276 JUN/FOS $\quad$ JUN $\quad$ CREB1 $\quad$ FOS 13,044,276 CCCAGCTTCC AgGgGTGACT GTGCCTCTGA CGTCAGACGg TTTTTGGGTC ATTCCCTGGC ACGGgGACTT TATTTCATA 13,044,356 ACAGCATGAA GTGCCGTGGA ACTGGAATAG GCGTGTCCTC TCCCTCGACC CTCCCCCTCC TTGTCCCTCT GCTCACCCCT 13,044,436 CGCTCGTTC CTCCCTCCGg CGAGgGCCGC CTTTATAACA ACTGCTCAGA GTGCGAGGGC GGGATAGCTG TCCAAGGTCT 13,044,516 CCCCCAGCAC TGAGGAGCTC GCCTGCTGCC CTCTTGCGCG CGGGAAGCAG CACCAAGTTC ACGGCCAACG CCTTGGCACT 13,044,596 AGG

Figure 3: Chromosomal locus, gene architecture and transcription factor binding information. A. $G P R C 5 A$ gene (ENSG00000013588) location is chromosome 12:13,030,138-13,084,449. B. RAR/RXR binding site, CREB binding site, TP53 binding sites, BRCA1 binding sites, FOS/JUN binding sites, and MYC binding site are located between 13,043,716 and 13,044,596. C. GPRC5A mRNA (ENST00000014914) is spliced from the region between 13,043,716 and 13,070,871. Transcription factor information was compiled using data from the ENCODE project predictions from JASPAR [92]. 
mouse lung cells inhibits SOCS3 expression, which leads to persistent STAT3 activation under stimulation and up-regulation of STAT3-regulated cell survival genes, resulting in cell transformation and resistance to cell death [58, 60-62]. Besides, in GPRC5A knockout mouse lung cells, both basal NF- $\kappa \mathrm{B}$ activation and lipopolysaccharideinduced $\mathrm{NF}-\kappa \mathrm{B}$ activation are elevated [59]. Enhanced NF-B activation up-regulates multiple NF- $\kappa \mathrm{B}$ target genes in cells, leading to increased inflammation $[42,59,63]$.

Besides STAT3 and NF- $\mathrm{B}$ signaling pathway, GPRC5A is involved in regulating the cell cycle. It probably achieves this through FEN1, MCM2, CCND1 and $U B E 2 C$ as the expression of these genes is upregulated following loss of GPRC5A expression in lung adenocarcinoma [64]. But a detailed understanding of the regulatory mechanism is still lacking.

The GPRC5A protein is also post-translationally modified. For example, it is known that the amino acid residues S301 and S345 are phosphorylated during mitosis [65-68] - see also Figure 4. Phosphorylation of GPRC5A may play a role during cell cycle progression. Besides phosphorylation, N-linked glycosylation probably occurs at R158. Recent studies show that GPRC5A could also be ubiquitinated at K285, K333, K348 and K353 [69-74], but detailed mechanisms and functional roles of GPRC5A ubiquitination are not yet available.

GPRC5A also interacts with multiple proteins in vivo. Among the probable interacting partners of GPRC5A are EIF4A1 and HSPA9 [75]. In addition, it has been shown that GPRC5A is co-fractionated with

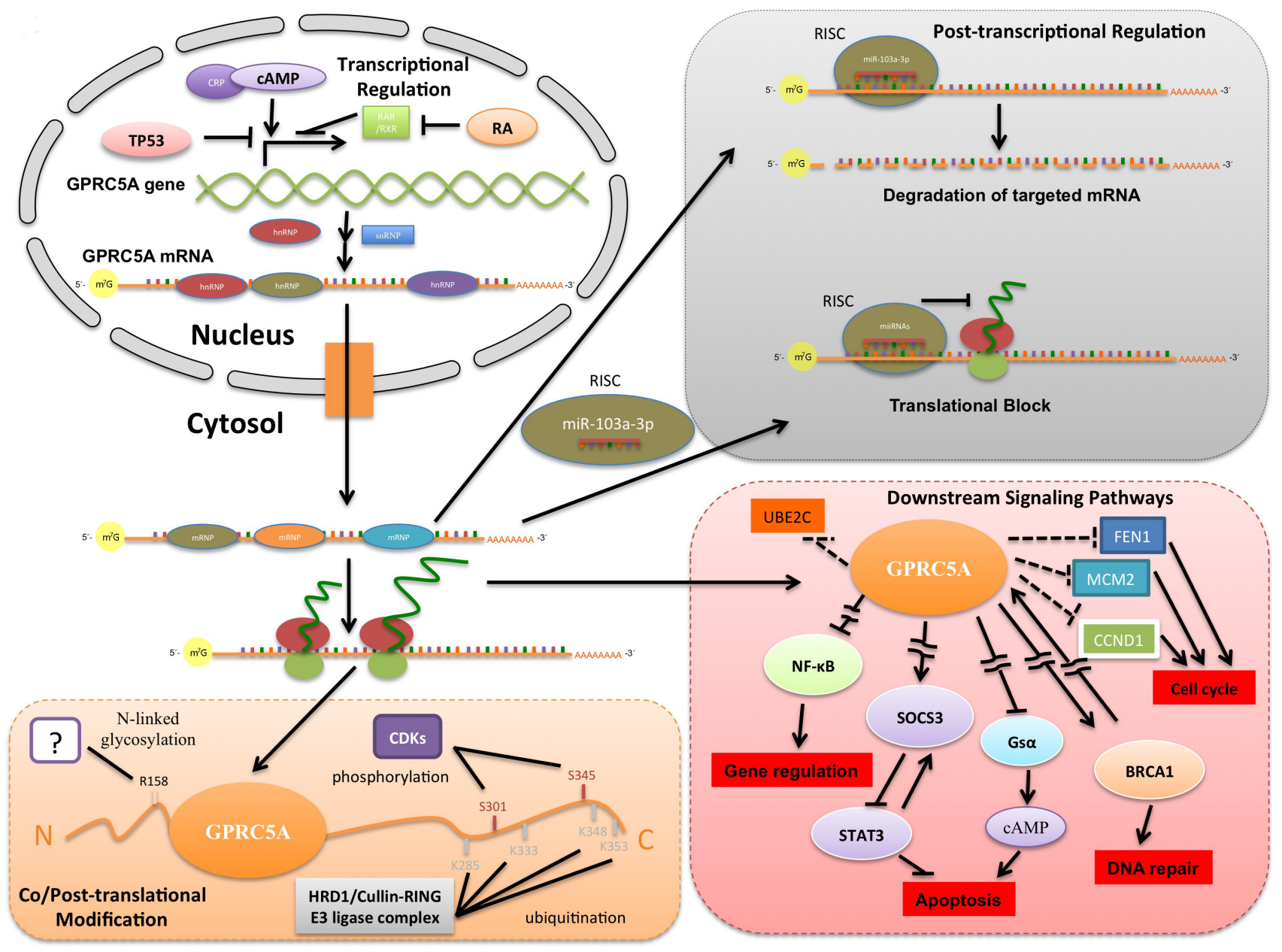

Figure 4: A systemic view of GPRC5A's activity. In the nucleus, TP53 inhibits $G P R C 5 A$ gene transcription by binding to $G P R C 5 A$ 's promoter region. On the other hand, cAMP promotes GPRC5A's transcription by binding to the latter's promoter region along with cAMP receptor protein (CRP). RA binding to RAR/RXRs results in dissociation of co-repressor and recruitment of co-activator proteins that in turn promotes GPRC5A gene transcription. In the cytosol, GPRC5A mRNA is targeted by miR-103a-3p, resulting mainly in mRNA degradation. GPRC5A protein is phosphorylated at S301 and S345 during mitosis by cyclin-dependent kinases. In addition, R158 in GPRC5A is likely glycosylated in vivo. Also, L285, L333, L348 and L353 at the C-terminus of GPRC5A might be ubiquitinated by the HRD1/Cullin-Ring E3 ligase complex. With regard to downstream signaling pathways, GPRC5A could promote SOCS3 and BRCA1 expression while inhibiting NF- $\mathrm{B}$ and Gs $\alpha$ expression, but details of this mechanism are lacking. GPRC5A may also inhibit UBE2C, FEN1, MCM2 and CCND1 expression based on previously reported indirect evidence [64]. Arrows in this diagram represent up-regulation or activation. T-joints indicate down-regulation or inhibition (direct evidence) whereas dashed T-joints indicates the available evidence is indirect. Interrupted lines indicate a connection that involves one or more intermediate pathways. 
Table 2: Dysregulation of GPRC5A in different diseases.

\begin{tabular}{|c|c|c|c|}
\hline Disease & $\begin{array}{c}\text { Level } \\
\text { Cancer vs. Normal }\end{array}$ & Methods & Reference \\
\hline Oral Squamous Cell Carcinoma & db & $\mathrm{IHC}$ & [10] \\
\hline Non-Small Cell Lung Carcinoma & db & Microarray; qRT-PCR; & {$[78,85]$} \\
\hline Chronic Obstructive Pulmonary Disease & तh & Microarray; qRT-PCR; & [85] \\
\hline Breast Carcinoma" & b & NGS;RT-PCR & [13] \\
\hline Primary Myelodysplastic Syndrome & d & Microarray & [86] \\
\hline Hepatocellular Carcinoma & $N / A^{(d)}$ & Microarray & [8] \\
\hline Hepatocellular Carcinoma & db & qRT-PCR & [84] \\
\hline Colorectal Adenocarcinoma & 9 & LC-MS/MS & [12] \\
\hline Breast Carcinoma (Primary) & q & Microarray & [81] \\
\hline Breast Carcinoma (Invasive) & $\uparrow$ & CPA; IHC & [82] \\
\hline Colorectal Adenocarcinoma & $q$ & LC-MS/MS;IHC & [5] \\
\hline Atherosclerosis ${ }^{(a)}$ & q & Microarray & [9] \\
\hline Gastric Carcinoma & qp & Microarray; qRT-PCR; & [7] \\
\hline Breast Carcinoma & $\uparrow$ & qRT-PCR & [80] \\
\hline Intrahepatic Cholangiocarcinoma & q & Microarray; qRT-PCR & [11] \\
\hline Pancreatic Ductal Adenocarcinoma ${ }^{\text {(b) }}$ & $\uparrow$ & Microarray & [27] \\
\hline Breast Carcinoma ${ }^{(\mathrm{c})}$ & q & Microarray; qRT-PCR & [27] \\
\hline Hepatocellular Carcinoma & $\widehat{a p}$ & qRT-PCR; WB; IHC & [83] \\
\hline
\end{tabular}

${ }^{(\#)}$ BRCA1 5382ins C mutation carriers vs. BRCA1 wild-type patients. ${ }^{(a)}$ The SMC cell line is analyzed in this study. ${ }^{\text {(b) }}$ Pancreatic cell lines are analyzed in this study. ${ }^{(\mathrm{c})}$ Breast cell lines are analyzed in this study. ${ }^{(\mathrm{d})}$ GPRC5A expression level is compared within patients before treatment and after treatment. GPRC5A is up-regulated after treatment.

GTF2F2, MPV17, NOLC1, and SLC25A3 under certain experimental conditions. In other experiments, GPRC5A was shown to interact with TRIM69 or UBC [69-74, 76, 77].

\section{GPRC5A and its elucidated roles in diseases}

We next review the current body of literature regarding the involvement of GPRC5A in various diseases (Table 2).

- GPRC5A and non-small cell lung carcinoma: In non-small cell lung carcinoma (NSCLC), GPRC5 $A$ mRNA levels are lower than in adjacent normal tissues [78]. Ectopic overexpression of GPRC5A in NSCLC cell line H1792 reduces cells' growth in soft agar. In addition, homozygous GPRC5A knockout mice are much more prone to develop lung tumors at 1-2 years of age than heterozygous or wild type mice. But deficiency of GPRC5A does not cause significant developmental defects in the lungs of mice [79]. Other parallel studies have shown that knockout of GPRC5A in mice leads to activation of $\mathrm{NF}-\kappa \mathrm{B}$, promoting lung inflammation and tumorigenesis, and enhances the transformed phenotype in normal and malignant lung epithelial cells through STAT3 signaling pathway $[58,59]$. Studies also show that lung tumorigenesis in the GPRC5A-KO mouse model is augmented by nicotine-derived nitrosamine ketone (NNK) and that gene expression changes are induced by tobacco carcinogens [64].
- GPRC5A and oral squamous cell carcinoma: $G P R C 5 A$ expression level is very high in normal oral tissue, especially in differentiated areas whereas in oral squamous cell carcinoma (OSCC) its expression is repressed [10]. In OSCC, GPRC5A expression is negatively correlated to OSCC's differential level. In vitro experiments revealed that overexpression of GPRC5A in OSCC CAL27 cells suppresses the cells' anchorageindependent growth activity, indicating that GPRC5A plays a tumor suppressor role in oral tissue.

- GPRC5A and breast cancer: The evidence so far regarding GPRC5A's role in breast cancer has been conflicting. In one breast cancer study [80] it was shown that GPRC5A mRNA is up-regulated in 19 of 25 primary breast cancers and in 6 of 11 breast cancer cell lines examined, compared with normal mammary gland tissue. Moreover, knockdown of GPRC5A by small interfering RNA (siRNA) in breast cancer cell lines MCF7 and T47D suppressed cancer cells' growth [80]. Another group found that in breast cancer, the expression of GPRC5A along with that of PYCARD and FXYD3 can serve as a good predictor of treatment outcome and enhances the predictive power of tumor size [81]. However, another study [82] reported that although GPRC5A expression is up-regulated in breast cancer, its expression level is not associated with tumor stage, lymph node status, histological grading or histological tumor type, or with overall and recurrence-free survival. Another recent study showed that the germline inactivating mutation c. $183 \mathrm{delG}$ of GPRC5A is enriched in breast cancer patients carrying 
the 5382insC allele of BRCA1 [13]. Lastly, in vitro experiments revealed that GPRC5A is involved in forming radiation-induced BRCA1 and RAD51 DNA repair foci and that knockdown of GPRC5A attenuates DNA repair foci in cells following radiation [13].

- GPRC5A and colorectal cancer: In normal colon tissue, GPRC5A is expressed at low levels [1]. The majority of colon epithelium is negative or weak for GPRC5A expression, while only neuroendocrine cells within the colonic crypts show high expression level on plasma membrane [5]. In colorectal cancer, GPRC5A is abundantly present in tumor epithelium with the neuroendocrine cells showing strong staining on the plasma membrane [5]. Within neoplastic epithelium, its localization pattern is variable with most colorectal cancer tissues displaying diffuse cytoplasmic expression. Strong cytoplasmic expression of GPRC5A in colorectal cancer tissues is significantly associated with disease recurrence in Dukes' A-C (stage 1-3) patients when compared to low or negative expression of GPRC5A in cancer tissues. In another study, 33 cases of primary colorectal cancer and 16 colon polyps were subjected to LC-MS/MS analysis [12]. In these samples, GPRC5A level is higher in both metastatic and non-metastatic colorectal cancer than it is in polyps indicating that GPRC5A could be used as a biomarker in the diagnosis of colorectal cancer.

- GPRC5A and gastric cancer: In normal small intestine, $G P R C 5 A$ is expressed at very low levels whereas in gastric cancer tissues GPRC5A is elevated significantly [7]. The pattern of GPRC5A expression in gastric cancer tissues is quite different from that of normal mucosa and of adjacent noncancerous lesion samples. This raises the possibility that GPRC5A can be used as a potential biomarker and a treatment target for gastric cancer based on its membrane localization and its association with cancer cell proliferation.

- GPRC5A and hepatocellular carcinoma: Based on the currently available evidence it is not clear whether in liver GPRC5A acts an oncogene or as tumor suppressor. In one study, it was reported that $G P R C 5 A$ expression is higher in hepatocellular carcinoma (HCC) than in paratumor or in normal liver tissues [83]. Higher expression of GPRC5A is associated with lower overall and diseasefree survival rate in $\mathrm{HCC}$ patients [83]. However, in another study researchers reported that GPRC5A mRNA levels are lower in seven newly established cell lines from patient derived tumor xenografts [84]. Yet another study showed that GPRC5A mRNA levels are higher in HCC patients after 8-week treatment with peretinoin and that the expression of 233 genes including GPRC5A could classify patients into one of two groups, recurrence vs. non-recurrence, with a prediction accuracy rate of $79.6 \%$ [8].

- GPRC5A and other diseases: In chronic obstructive pulmonary disease (COPD) patients, the levels of GPRC5A protein were significantly lower in normal bronchial epithelia (NBE) compared with healthy controls [85]. As the levels of GPRC5A mRNA decrease from normal people to patients with either COPD or adenocarcinoma it is likely that in this context GPRC5A acts as a tumor suppressor. On the other hand, in intrahepatic cholangiocarcinoma (ICC), GPRC5A mRNA levels are higher than in normal tissue [11] suggesting that they could serve as a novel biomarker for classifying and diagnosing this highly fatal type of carcinoma. In myelodysplastic syndrome (MDS), GPRC5A mRNA levels were found to be lower in CD34+ cells, which could explain these cells' susceptibility to cell damage [86].

\section{CONCLUSION}

The GPRC5A gene is conserved from mammals to fish [14]. In the disease context, GPRC5A was originally reported as a tumor suppressor in non-small cell lung carcinoma. Later its tumor suppressor ability was also shown in oral squamous cell carcinoma. Subsequent reports indicated that in breast cancer, colorectal cancer and pancreatic cancer GPRC5A could also behave as an oncogene. This dual behavior makes GPRC5A a very interesting gene to study. Nonetheless, its likely interactions with many other factors some of which may be present in some cell types and absent in other cell types suggest that a lot more research work will be required to understand how this dual behavior arises. Recent research efforts revealed that mRNA transcripts could play additional important roles, besides their protein coding ability, by decoying miRNAs [87-91]. As the GPRC5A's mRNA contains many putative miRNA-binding sites it is conceivable that some of its functional roles are effected through the decoying of one or more miRNAs. To prove this hypothesis and to elucidate the regulatory roles of GPRC5A mRNA and protein additional research is needed.

Not surprisingly considering that GPRC5A was originally identified as a retinoid acid induced molecule, GPRC5A contains a RAR/RXR binding site [1]. In addition, GPRC5A's expression is suppressed by p53 and mutation of p53 leads to increased levels of GPRC5A in p53-mutant breast cancer cells [27]. Furthermore, as the GPRC5A locus is favored by multiple other transcription factors such as BRCA1, FOS, JUN and MYC, dysregulation of one or more of these transcription factors may lead to abnormal expression of GPRC5A [13, $29,38,45]$.

With respect to post-transcriptional regulation, we recently reported that $\mathrm{miR}-103 \mathrm{a}-3 \mathrm{p}$ can regulate GPRC5A protein expression by targeting the 5'UTR of GPRC5A's mRNA. This finding suggests that to understand GPRC5A's post-transcriptional regulation one needs to consider miRNA targets beyond its mRNA's 3'UTR. Moreover, RBPs and possibly lncRNAs might also be involved in regulating GPRC5A. However, no such interactions are currently known. 
With respect to post-translational modification, several articles report that GPRC5A protein is phosphorylated at S301 and S345 during mitosis [6568]. N-glycosylation and uniquitination also occur but the physiological functions of these modifications remain unclear.

With respect to its participation in signaling pathways relatively little information is currently available. One line of work reported that GPRC5A expression impacts on the cAMP signaling pathway [28]. In another line of work it was shown that knocking out GPRC5A leads to the activation of the NF- $\mathrm{kB}$ and STAT3 signaling pathways and results in cell proliferation and resistance to cell death $[58,59]$. Additionally, loss of GPRC5A could result in up-regulation of FEN1, MCM2, $C C N D 1$ and $U B E 2 C$, all of who are involved in cell cycle regulation [64]. However, it is still unknown how exactly GPRC5A interacts these pathways.

Some of the previous studies attempted to find a potential ligand for GPRC5A [15, 28, 58] but without success. In addition, it is unclear how GPRC5A is activated. As this gene is found to be dysregulated in many cancers we expect that further studies will provide additional insights about its post-transcriptional and post-translational regulation and function. In turn these findings will help advance the diagnosis and eventually the treatment of cancers through the manipulation of key stages of this protein's lifecycle.

\section{ACKNOWLEDGEMENTS}

The work was supported in part by a W. M. Keck Foundation grant (IR), a Hirshberg Foundation for Pancreatic Cancer Research award (IR), and by institutional funds.

\section{REFERENCES}

1. Cheng $\mathrm{Y}$ and Lotan R. Molecular cloning and characterization of a novel retinoic acid-inducible gene that encodes a putative $\mathrm{G}$ protein-coupled receptor. The Journal of biological chemistry. 1998; 273(52):35008-35015.

2. Gonzales PA, Pisitkun T, Hoffert JD, Tchapyjnikov D, Star RA, Kleta R, Wang NS and Knepper MA. Large-scale proteomics and phosphoproteomics of urinary exosomes. Journal of the American Society of Nephrology : JASN. 2009; 20(2):363-379.

3. Gonzalez-Begne M, Lu B, Han X, Hagen FK, Hand AR, Melvin JE and Yates JR. Proteomic analysis of human parotid gland exosomes by multidimensional protein identification technology (MudPIT). Journal of proteome research. 2009; 8(3):1304-1314.

4. Prunotto M, Farina A, Lane L, Pernin A, Schifferli J, Hochstrasser DF, Lescuyer P and Moll S. Proteomic analysis of podocyte exosome-enriched fraction from normal human urine. Journal of proteomics. 2013; 82:193229.

5. Zougman A, Hutchins GG, Cairns DA, Verghese E, Perry SL, Jayne DG, Selby PJ and Banks RE. Retinoic acidinduced protein 3: identification and characterisation of a novel prognostic colon cancer biomarker. European journal of cancer. 2013; 49(2):531-539.

6. Acquafreda T, Soprano KJ and Soprano DR. GPRC5A: A potential tumor suppressor and oncogene. Cancer biology \& therapy. 2009; 8(10):963-965.

7. Cheng L, Yang S, Yang Y, Zhang W, Xiao H, Gao H, Deng $\mathrm{X}$ and Zhang Q. Global gene expression and functional network analysis of gastric cancer identify extended pathway maps and GPRC5A as a potential biomarker. Cancer letters. 2012; 326(1):105-113.

8. Honda M, Yamashita T, Yamashita T, Arai K, Sakai Y, Sakai A, Nakamura M, Mizukoshi E and Kaneko S. Peretinoin, an acyclic retinoid, improves the hepatic gene signature of chronic hepatitis C following curative therapy of hepatocellular carcinoma. BMC cancer. 2013; 13:191.

9. Karagiannis GS, Weile J, Bader GD and Minta J. Integrative pathway dissection of molecular mechanisms of moxLDLinduced vascular smooth muscle phenotype transformation. BMC cardiovascular disorders. 2013; 13:4.

10. Liu SL, Zhong SS, Ye DX, Chen WT, Zhang ZY and Deng J. Repression of G protein-coupled receptor family C group 5 member $\mathrm{A}$ is associated with pathologic differentiation grade of oral squamous cell carcinoma. Journal of oral pathology \& medicine : official publication of the International Association of Oral Pathologists and the American Academy of Oral Pathology. 2013; 42(10):761768.

11. Subrungruanga I, Thawornkunob C, ChawalitchewinkoonPetmitrc P, Pairojkul C, Wongkham S and Petmitrb S. Gene expression profiling of intrahepatic cholangiocarcinoma. Asian Pacific journal of cancer prevention : APJCP. 2013; 14(1):557-563.

12. Kume H, Muraoka S, Kuga T, Adachi J, Narumi R, Watanabe S, Kuwano M, Kodera Y, Matsushita K, Fukuoka J, Masuda T, Ishihama Y, Matsubara H, Nomura F and Tomonaga T. Discovery of Colorectal Cancer Biomarker Candidates by Membrane Proteomic Analysis and Subsequent Verification using Selected Reaction Monitoring (SRM) and Tissue Microarray (TMA) Analysis. Molecular \& cellular proteomics : MCP. 2014; 13(6):1471-1484.

13. Sokolenko AP, Bulanova DR, Iyevleva AG, Aleksakhina $\mathrm{SN}$, Preobrazhenskaya EV, Ivantsov AO, Kuligina E, Mitiushkina NV, Suspitsin EN, Yanus GA, Zaitseva OA, Yatsuk OS, Togo AV, Kota P, Dixon JM, Larionov AA, et al. High prevalence of GPRC5A germline mutations in BRCA1-mutant breast cancer patients. International journal of cancer Journal international du cancer. 2014; 134(10):2352-2358.

14. Kurtenbach S, Mayer C, Pelz T, Hatt H, Leese F and Neuhaus EM. Molecular evolution of a chordate specific 
family of G protein-coupled receptors. BMC evolutionary biology. 2011; 11:234.

15. Brauner-Osborne H, Jensen AA, Sheppard PO, Brodin B, Krogsgaard-Larsen $\mathrm{P}$ and O'Hara P. Cloning and characterization of a human orphan family C G-protein coupled receptor GPRC5D. Biochimica et biophysica acta. 2001; 1518(3):237-248.

16. Brauner-Osborne $\mathrm{H}$ and Krogsgaard-Larsen P. Sequence and expression pattern of a novel human orphan G-proteincoupled receptor, GPRC5B, a family C receptor with a short amino-terminal domain. Genomics. 2000; 65(2):121-128.

17. Dohlman HG, Thorner J, Caron MG and Lefkowitz RJ. Model systems for the study of seven-transmembranesegment receptors. Annual review of biochemistry. 1991; 60:653-688.

18. Fredriksson R, Lagerstrom MC, Lundin LG and Schioth HB. The G-protein-coupled receptors in the human genome form five main families. Phylogenetic analysis, paralogon groups, and fingerprints. Molecular pharmacology. 2003; 63(6):1256-1272.

19. Ye X, Tao Q, Wang Y, Cheng Y and Lotan R. Mechanisms underlying the induction of the putative human tumor suppressor GPRC5A by retinoic acid. Cancer biology \& therapy. 2009; 8(10):951-962.

20. Germain P, Chambon P, Eichele G, Evans RM, Lazar MA, Leid M, De Lera AR, Lotan R, Mangelsdorf DJ and Gronemeyer H. International Union of Pharmacology. LX. Retinoic acid receptors. Pharmacological reviews. 2006; 58(4):712-725.

21. Allenby G, Bocquel MT, Saunders M, Kazmer S, Speck J, Rosenberger M, Lovey A, Kastner P, Grippo JF, Chambon $\mathrm{P}$ and et al. Retinoic acid receptors and retinoid $\mathrm{X}$ receptors: interactions with endogenous retinoic acids. Proceedings of the National Academy of Sciences of the United States of America. 1993; 90(1):30-34.

22. Hembree JR, Agarwal C, Beard RL, Chandraratna RA and Eckert R. Retinoid X receptor-specific retinoids inhibit the ability of retinoic acid receptor-specific retinoids to increase the level of insulin-like growth factor binding protein-3 in human ectocervical epithelial cells. Cancer research. 1996; 56(8):1794-1799.

23. Kizaki M, Dawson MI, Heyman R, Elster E, Morosetti R, Pakkala S, Chen DL, Ueno H, Chao W, Morikawa M, Ikeda Y, Heber D, Pfahl M and Koeffler HP. Effects of novel retinoid $\mathrm{X}$ receptor-selective ligands on myeloid leukemia differentiation and proliferation in vitro. Blood. 1996; 87(5):1977-1984.

24. Melino G, Draoui M, Bernardini S, Bellincampi L, Reichert $\mathrm{U}$ and Cohen P. Regulation by retinoic acid of insulindegrading enzyme and of a related endoprotease in human neuroblastoma cell lines. Cell growth \& differentiation : the molecular biology journal of the American Association for Cancer Research. 1996; 7(6):787-796.

25. Meyer M, Sonntag-Buck V, Keaveney M and Stunnenberg HG. Retinoid-dependent transcription: the RAR/RXR-TBP-
EIA/EIA-LA connection. Biochemical Society symposium. 1996; 62:97-109.

26. Botling J, Castro DS, Oberg F, Nilsson K and Perlmann T. Retinoic acid receptor/retinoid X receptor heterodimers can be activated through both subunits providing a basis for synergistic transactivation and cellular differentiation. The Journal of biological chemistry. 1997; 272(14):9443-9449.

27. Wu Q, Ding W, Mirza A, Van Arsdale T, Wei I, Bishop WR, Basso A, McClanahan T, Luo L, Kirschmeier P, Gustafson E, Hernandez M and Liu S. Integrative genomics revealed RAI3 is a cell growth-promoting gene and a novel P53 transcriptional target. The Journal of biological chemistry. 2005; 280(13):12935-12943.

28. Hirano M, Zang L, Oka T, Ito Y, Shimada Y, Nishimura $\mathrm{Y}$ and Tanaka $\mathrm{T}$. Novel reciprocal regulation of cAMP signaling and apoptosis by orphan G-protein-coupled receptor GPRC5A gene expression. Biochemical and biophysical research communications. 2006; 351(1):185191.

29. Mullan PB, Quinn JE and Harkin DP. The role of BRCA1 in transcriptional regulation and cell cycle control. Oncogene. 2006; 25(43):5854-5863.

30. Houvras Y, Benezra M, Zhang H, Manfredi JJ, Weber BL and Licht JD. BRCA1 physically and functionally interacts with ATF1. The Journal of biological chemistry. 2000; 275(46):36230-36237.

31. Lechner MS, Levitan I and Dressler GR. PTIP, a novel BRCT domain-containing protein interacts with Pax 2 and is associated with active chromatin. Nucleic acids research. 2000; 28(14):2741-2751.

32. Maor SB, Abramovitch S, Erdos MR, Brody LC and Werner H. BRCA1 suppresses insulin-like growth factor-I receptor promoter activity: potential interaction between BRCA1 and Sp1. Molecular genetics and metabolism. 2000; 69(2):130-136.

33. Schlegel BP, Green VJ, Ladias JA and Parvin JD. BRCA1 interaction with RNA polymerase II reveals a role for hRPB2 and hRPB10alpha in activated transcription. Proceedings of the National Academy of Sciences of the United States of America. 2000; 97(7):3148-3153.

34. MacLachlan TK, Takimoto R and El-Deiry WS. BRCA1 directs a selective p53-dependent transcriptional response towards growth arrest and DNA repair targets. Molecular and cellular biology. 2002; 22(12):4280-4292.

35. Cable PL, Wilson CA, Calzone FJ, Rauscher FJ, 3rd, Scully R, Livingston DM, Li L, Blackwell CB, Futreal PA and Afshari CA. Novel consensus DNA-binding sequence for BRCA1 protein complexes. Molecular carcinogenesis. 2003; 38(2):85-96.

36. Ouchi T, Lee SW, Ouchi M, Aaronson SA and Horvath CM. Collaboration of signal transducer and activator of transcription 1 (STAT1) and BRCA1 in differential regulation of IFN-gamma target genes. Proceedings of the National Academy of Sciences of the United States of America. 2000; 97(10):5208-5213. 
37. Pao GM, Janknecht $\mathrm{R}$, Ruffner $\mathrm{H}$, Hunter $\mathrm{T}$ and Verma IM. CBP/p300 interact with and function as transcriptional coactivators of BRCA1. Proceedings of the National Academy of Sciences of the United States of America. 2000; 97(3):1020-1025.

38. Shaulian E and Karin M. AP-1 in cell proliferation and survival. Oncogene. 2001; 20(19):2390-2400.

39. Karin M, Liu $Z$ and Zandi E. AP-1 function and regulation. Current opinion in cell biology. 1997; 9(2):240-246.

40. Brauner-Osborne H, Jensen AA, Sheppard PO, O'Hara P and Krogsgaard-Larsen $\mathrm{P}$. The agonist-binding domain of the calcium-sensing receptor is located at the aminoterminal domain. The Journal of biological chemistry. 1999; 274(26):18382-18386.

41. Salvat C, Aquaviva C, Jariel-Encontre I, Ferrara P, Pariat M, Steff AM, Carillo S and Piechaczyk M. Are there multiple proteolytic pathways contributing to c-Fos, c-Jun and p53 protein degradation in vivo? Molecular biology reports. 1999; 26(1-2):45-51.

42. Hu Y, Jin X and Snow ET. Effect of arsenic on transcription factor AP-1 and NF-kappaB DNA binding activity and related gene expression. Toxicology letters. 2002; 133(1):33-45.

43. Zhang $\mathrm{W}$ and Liu HT. MAPK signal pathways in the regulation of cell proliferation in mammalian cells. Cell research. 2002; 12(1):9-18.

44. Ye X and Lotan R. Potential misinterpretation of data on differential gene expression in normal and malignant cells in vitro. Briefings in functional genomics \& proteomics. 2008; 7(4):322-326.

45. Ji H, Wu G, Zhan X, Nolan A, Koh C, De Marzo A, Doan HM, Fan J, Cheadle C, Fallahi M, Cleveland JL, Dang $\mathrm{CV}$ and Zeller KI. Cell-type independent MYC target genes reveal a primordial signature involved in biomass accumulation. PloS one. 2011; 6(10):e26057.

46. Chen K and Rajewsky N. The evolution of gene regulation by transcription factors and microRNAs. Nature reviews Genetics. 2007; 8(2):93-103.

47. Zhou H and Rigoutsos I. MiR-103a-3p targets the 5' UTR of GPRC5A in pancreatic cells. Rna. 2014.

48. Miranda KC, Huynh T, Tay Y, Ang YS, Tam WL, Thomson AM, Lim B and Rigoutsos I. A pattern-based method for the identification of MicroRNA binding sites and their corresponding heteroduplexes. Cell. 2006; 126(6):12031217.

49. Loher P and Rigoutsos I. Interactive exploration of RNA22 microRNA target predictions. Bioinformatics. 2012; 28(24):3322-3323.

50. Dreyfuss G, Kim VN and Kataoka N. Messenger-RNAbinding proteins and the messages they carry. Nature reviews Molecular cell biology. 2002; 3(3):195-205.

51. Geisler S and Coller J. RNA in unexpected places: long non-coding RNA functions in diverse cellular contexts. Nature reviews Molecular cell biology. 2013; 14(11):699-
712.

52. Yoon JH, Abdelmohsen $\mathrm{K}$ and Gorospe $\mathrm{M}$. Posttranscriptional gene regulation by long noncoding RNA. Journal of molecular biology. 2013; 425(19):37233730 .

53. Clark BS and Blackshaw S. Long non-coding RNAdependent transcriptional regulation in neuronal development and disease. Frontiers in genetics. 2014; $5: 164$.

54. Krishnan J and Mishra RK. Emerging trends of long noncoding RNAs in gene activation. The FEBS journal. 2014; 281(1):34-45.

55. Storz G, Opdyke JA and Zhang A. Controlling mRNA stability and translation with small, noncoding RNAs. Current opinion in microbiology. 2004; 7(2):140-144.

56. Brennan CM and Steitz JA. HuR and mRNA stability. Cellular and molecular life sciences : CMLS. 2001; 58(2):266-277.

57. Mercer TR, Dinger ME and Mattick JS. Long non-coding RNAs: insights into functions. Nature reviews Genetics. 2009; 10(3):155-159.

58. Chen Y, Deng J, Fujimoto J, Kadara H, Men T, Lotan D and Lotan R. Gprc5a deletion enhances the transformed phenotype in normal and malignant lung epithelial cells by eliciting persistent Stat3 signaling induced by autocrine leukemia inhibitory factor. Cancer research. 2010; 70(21):8917-8926.

59. Deng J, Fujimoto J, Ye XF, Men TY, Van Pelt CS, Chen YL, Lin XF, Kadara H, Tao Q, Lotan D and Lotan R. Knockout of the tumor suppressor gene Gprc5a in mice leads to NF-kappaB activation in airway epithelium and promotes lung inflammation and tumorigenesis. Cancer prevention research. 2010; 3(4):424-437.

60. Brender C, Nielsen M, Kaltoft K, Mikkelsen G, Zhang Q, Wasik M, Billestrup N and Odum N. STAT3-mediated constitutive expression of SOCS-3 in cutaneous T-cell lymphoma. Blood. 2001; 97(4):1056-1062.

61. Niwa Y, Kanda H, Shikauchi Y, Saiura A, Matsubara K, Kitagawa T, Yamamoto J, Kubo T and Yoshikawa H. Methylation silencing of SOCS-3 promotes cell growth and migration by enhancing JAK/STAT and FAK signalings in human hepatocellular carcinoma. Oncogene. 2005; 24(42):6406-6417.

62. Kim G, Ouzounova M, Quraishi AA, Davis A, Tawakkol N, Clouthier SG, Malik F, Paulson AK, D'Angelo RC, Korkaya S, Baker TL, Esen ES, Prat A, Liu S, Kleer CG, Thomas DG, et al. SOCS3-mediated regulation of inflammatory cytokines in PTEN and p53 inactivated triple negative breast cancer model. Oncogene. 2014.

63. Saile B, Matthes N, El Armouche H, Neubauer K and Ramadori G. The bcl, NFkappaB and p53/p21WAF1 systems are involved in spontaneous apoptosis and in the anti-apoptotic effect of TGF-beta or TNF-alpha on activated hepatic stellate cells. European journal of cell biology. 2001; 80(8):554-561. 
64. Fujimoto J, Kadara H, Men T, van Pelt C, Lotan D and Lotan R. Comparative functional genomics analysis of NNK tobacco-carcinogen induced lung adenocarcinoma development in Gprc5a-knockout mice. PloS one. 2010; 5(7): 11847.

65. Oppermann FS, Grundner-Culemann K, Kumar C, Gruss OJ, Jallepalli PV and Daub H. Combination of chemical genetics and phosphoproteomics for kinase signaling analysis enables confident identification of cellular downstream targets. Molecular \& cellular proteomics : MCP. 2012; 11(4):O111 012351.

66. Olsen JV, Vermeulen M, Santamaria A, Kumar C, Miller ML, Jensen LJ, Gnad F, Cox J, Jensen TS, Nigg EA, Brunak S and Mann M. Quantitative phosphoproteomics reveals widespread full phosphorylation site occupancy during mitosis. Science signaling. 2010; 3(104):ra3.

67. Shiromizu T, Adachi J, Watanabe S, Murakami T, Kuga $\mathrm{T}$, Muraoka S and Tomonaga T. Identification of missing proteins in the neXtProt database and unregistered phosphopeptides in the PhosphoSitePlus database as part of the Chromosome-centric Human Proteome Project. Journal of proteome research. 2013; 12(6):2414-2421.

68. Dephoure N, Zhou C, Villen J, Beausoleil SA, Bakalarski CE, Elledge SJ and Gygi SP. A quantitative atlas of mitotic phosphorylation. Proceedings of the National Academy of Sciences of the United States of America. 2008; 105(31):10762-10767.

69. Wagner SA, Beli P, Weinert BT, Nielsen ML, Cox J, Mann $\mathrm{M}$ and Choudhary C. A proteome-wide, quantitative survey of in vivo ubiquitylation sites reveals widespread regulatory roles. Molecular \& cellular proteomics : MCP. 2011; 10(10):M111 013284.

70. Lee KA, Hammerle LP, Andrews PS, Stokes MP, Mustelin T, Silva JC, Black RA and Doedens JR. Ubiquitin ligase substrate identification through quantitative proteomics at both the protein and peptide levels. The Journal of biological chemistry. 2011; 286(48):41530-41538.

71. Kim W, Bennett EJ, Huttlin EL, Guo A, Li J, Possemato A, Sowa ME, Rad R, Rush J, Comb MJ, Harper JW and Gygi SP. Systematic and quantitative assessment of the ubiquitinmodified proteome. Molecular cell. 2011; 44(2):325-340.

72. Danielsen JM, Sylvestersen KB, Bekker-Jensen S, Szklarczyk D, Poulsen JW, Horn H, Jensen LJ, Mailand $\mathrm{N}$ and Nielsen ML. Mass spectrometric analysis of lysine ubiquitylation reveals promiscuity at site level. Molecular \& cellular proteomics : MCP. 2011; 10(3):M110 003590.

73. Emanuele MJ, Elia AE, Xu Q, Thoma CR, Izhar L, Leng Y, Guo A, Chen YN, Rush J, Hsu PW, Yen HC and Elledge SJ. Global identification of modular cullin-RING ligase substrates. Cell. 2011; 147(2):459-474.

74. Povlsen LK, Beli P, Wagner SA, Poulsen SL, Sylvestersen KB, Poulsen JW, Nielsen ML, Bekker-Jensen S, Mailand N and Choudhary C. Systems-wide analysis of ubiquitylation dynamics reveals a key role for PAF15 ubiquitylation in DNA-damage bypass. Nature cell biology. 2012;
14(10):1089-1098.

75. Havugimana PC, Hart GT, Nepusz T, Yang H, Turinsky AL, Li Z, Wang PI, Boutz DR, Fong V, Phanse S, Babu M, Craig SA, Hu P, Wan C, Vlasblom J, Dar VU, et al. A census of human soluble protein complexes. Cell. 2012; 150(5):10681081.

76. Hutchins JR, Toyoda Y, Hegemann B, Poser I, Heriche JK, Sykora MM, Augsburg M, Hudecz O, Buschhorn BA, Bulkescher J, Conrad C, Comartin D, Schleiffer A, Sarov M, Pozniakovsky A, Slabicki MM, et al. Systematic analysis of human protein complexes identifies chromosome segregation proteins. Science. 2010; 328(5978):593-599.

77. Meierhofer D, Wang X, Huang L and Kaiser P. Quantitative analysis of global ubiquitination in HeLa cells by mass spectrometry. Journal of proteome research. 2008; 7(10):4566-4576.

78. Tao Q, Fujimoto J, Men T, Ye X, Deng J, Lacroix L, Clifford JL, Mao L, Van Pelt CS, Lee JJ, Lotan D and Lotan $\mathrm{R}$. Identification of the retinoic acid-inducible Gprc5a as a new lung tumor suppressor gene. Journal of the National Cancer Institute. 2007; 99(22):1668-1682.

79. Xu J, Tian J and Shapiro SD. Normal lung development in RAIG1-deficient mice despite unique lung epitheliumspecific expression. American journal of respiratory cell and molecular biology. 2005; 32(5):381-387.

80. Nagahata T, Sato T, Tomura A, Onda M, Nishikawa K and Emi M. Identification of RAI3 as a therapeutic target for breast cancer. Endocrine-related cancer. 2005; 12(1):65-73.

81. Dairkee SH, Sayeed A, Luciani G, Champion S, Meng Z, Jakkula LR, Feiler HS, Gray JW and Moore DH. Immutable functional attributes of histologic grade revealed by contextindependent gene expression in primary breast cancer cells. Cancer research. 2009; 69(19):7826-7834.

82. Jorissen H, Bektas N, Dahl E, Hartmann A, ten Haaf A, Di Fiore S, Kiefer H, Thess A, Barth S and Klockenbring T. Production and characterisation of monoclonal antibodies against RAI3 and its expression in human breast cancer. BMC cancer. 2009; 9:200.

83. Zheng J, Guo X, Gao X, Liu H, Tu Y and Zhang Y. Overexpression of retinoic acid-induced protein 3 predicts poor prognosis for hepatocellular carcinoma. Clinical \& translational oncology : official publication of the Federation of Spanish Oncology Societies and of the National Cancer Institute of Mexico. 2014; 16(1):57-63.

84. Xin H, Wang K, Hu G, Xie F, Ouyang K, Tang X, Wang M, Wen D, Zhu Y and Qin X. Establishment and characterization of 7 novel hepatocellular carcinoma cell lines from patient-derived tumor xenografts. PloS one. 2014; 9(1):e85308.

85. Fujimoto J, Kadara H, Garcia MM, Kabbout M, Behrens C, Liu DD, Lee JJ, Solis LM, Kim ES, Kalhor N, Moran C, Sharafkhaneh A, Lotan R and Wistuba, II. G-protein coupled receptor family $\mathrm{C}$, group 5, member A (GPRC5A) expression is decreased in the adjacent field and normal bronchial epithelia of patients with chronic obstructive 
pulmonary disease and non-small-cell lung cancer. Journal of thoracic oncology : official publication of the International Association for the Study of Lung Cancer. 2012; 7(12):1747-1754.

86. Hofmann WK, de Vos S, Komor M, Hoelzer D, Wachsman $\mathrm{W}$ and Koeffler HP. Characterization of gene expression of CD34+ cells from normal and myelodysplastic bone marrow. Blood. 2002; 100(10):3553-3560.

87. Ling S, Birnbaum Y, Nanhwan MK, Thomas B, Bajaj M and Ye Y. MicroRNA-dependent cross-talk between VEGF and HIF1alpha in the diabetic retina. Cellular signalling. 2013; 25(12):2840-2847.

88. de Giorgio A, Krell J, Harding V, Stebbing J and Castellano L. Emerging roles of competing endogenous RNAs in cancer: insights from the regulation of PTEN. Molecular and cellular biology. 2013; 33(20):3976-3982.

89. Ala U, Karreth FA, Bosia C, Pagnani A, Taulli R, Leopold V, Tay Y, Provero P, Zecchina R and Pandolfi PP. Integrated transcriptional and competitive endogenous RNA networks are cross-regulated in permissive molecular environments. Proceedings of the National Academy of Sciences of the United States of America. 2013; 110(18):7154-7159.

90. Tay Y, Kats L, Salmena L, Weiss D, Tan SM, Ala U, Karreth F, Poliseno L, Provero P, Di Cunto F, Lieberman J, Rigoutsos I and Pandolfi PP. Coding-independent regulation of the tumor suppressor PTEN by competing endogenous mRNAs. Cell. 2011; 147(2):344-357.

91. Rigoutsos I and Furnari F. Gene-expression forum: Decoy for microRNAs. Nature. 2010; 465(7301):1016-1017.

92. Mathelier A, Zhao X, Zhang AW, Parcy F, Worsley-Hunt R, Arenillas DJ, Buchman S, Chen CY, Chou A, Ienasescu H, Lim J, Shyr C, Tan G, Zhou M, Lenhard B, Sandelin A, et al. JASPAR 2014: an extensively expanded and updated open-access database of transcription factor binding profiles. Nucleic acids research. 2014; 42(Database issue):D142-147. 